\title{
El municipio y el medio ambiente en América Latina
}

\section{Fernando Tudela*}

La crisis de los años ochenta nos obliga a enfrentar los grandes problemas, en apariencia muy diversos, que hoy inhiben los procesos de desarrollo en América Latina. Uno de ellos radica en la orientación fuertemente centralista de los Estados latinoamericanos, que condena a los gobiernos locales municipales a la marginalidad y a la virtual inoperancia. El segundo de los dos grandes problemas que se abordan en este ensayo se refiere al reciente deterioro ambiental, que en ultima instancia está determinado por el estilo de desa. rrollo que ha predominado en la región durante las últimas cuatro décadas.

El ensayo defiende la tesis de que ambos problemas deberian abordarse conjuntamente mediante una reforma descentralizadora y democrática del Estado. En este marco, el reforzamiento de las municipalidades y la asunción de su nueva función como promotoras del desarrollo a nivel local, permitirian una gestión ambiental integral, apegada al terreno $y$, por ende, respetuosa de la enorme diversidad de las situaciones sociales ecológi. cas que existen en América Latina. El ensayo incluye un análisis comparativo de la situación actual de las municipalidades en nueve paises latinoamericanos, asi como una revisión critica del pensamiento ambientalista en la región.

\section{El municipio y el medio ambiente en la crisis}

El deterioro de la institución municipal y del medio ambiente constituyen en América Latina procesos bastante generalizados y muy anteriores a la crisis de los años ochenta. Sin embargo, hoy sólo se pueden enfocar desde la perspectiva de dicha crisis, la peor que haya experimentado el conjunto de la región en el último medio siglo.

Por una parte, la crisis ha reducido los márgenes de tolerancia tradicionales frente a las carencias y los déficits crónicos. El efecto sinérgico de la caída del producto por habitante, la mayor polarización social, el aumento del subempleo y desempleo, la reducción del poder adquisitivo de la mayoría de la población, la compresión del gasto público y la merma consiguiente de las prestaciones sociales con cargo al Estado, se traduce en un deterioro de la calidad de vida en la región. En estas condiciones, surgen nuevas e imperiosas demandas, mientras muchas de las antiguas se presentan con renovada urgencia.

* Profesor-Investigador del Centro de Estudios Demográficos y de Desarrollo Urbano de El Colegio de México.

El antecedente inmediato de este trabajo se encuentra en el desarrollado por el mismo autor en agosto de 1986, para el Programa de las Naciones Unidas para el Medio Ambiente, que sirvió de base para la ponencia que presentó el PNuma en el 1er. Simposio Iberoamericano sobre medio ambiente y municipio, celebrado en octubre del mismo año en Iguazú, Argentina. Se agradece a las siguientes personas la información facilitada: Profra. Alejandra Massolo (UAM-Iztapalapa), Profra. Alicia Ziccardi (UNAM-1.L.), Dr. Raúl Olmedo (CNEM), Lic. Cristina González (CNEM), Ing. Luis Camacho (SIAP). 
Por otra parte, la crisis tiene dos caras, y en el anverso de la catástrofe se encuentra la oportunidad del cambio. Ni los conservadores más optimistas sueñan con mantener el statu quo sociopolítico anterior a la aparición de la crisis. Los más lúcidos de entre ellos hacen cálculos gatopardianos acerca de lo que habría que cambiar para que nada cambie, mientras las esperanzas de la mayoría se cifran en cambios estructurales más profundos.

Hasta ahora, la problemática ambiental y la municipal se habian abordado en forma independiente y con tiempos propios. Parece llegado el momento de relacionarlas, enfocándolas desde una perspectiva más amplia, en cuya ausencia sería imposible definir sàlidas a la actual crisis, de naturaleza global y estructural. La ya antigua "crisis del municipio" y la más reciente "crisis del medio ambiente" de la cual la región comienza a tomar conciencia en la década de los años setenta, no son sino facetas diferenciables de una misma problemática que ha limitado las perspectivas de desarrollo de la región y que se ha agudizado en los últimos años.

La que pudiéramos llamar "crisis del municipio" se refiere sobre todo a la creciente incapacidad de los gobiernos locales para asumir incluso las funciones más elementales de prestación de servicios públicos. Este problema afecta con mayor gravedad y desde hace más tiempo a las municipalidades, pero en distinta medida se manifiesta hoy en casi todas las instancias de gobierno. La crisis del municipio no es sino una faceta de la crisis del Estado, que en los casos más graves puede poner en entredicho su legitimidad y forzar a una reestructuración del mismo. Otro tanto sucede con la problemática ambiental. Ha sido mérito del pensamiento ambientalista latinoamericano la vinculación de los problemas del medio ambiente con la caracterización del estilo de desarrollo que predomina en la región. Lo que pudiera conocerse como "crisis ambiental" sería de hecho un aspecto de la crisis de ese estilo de desarrollo, que consiste en un deterioro muchas veces irreversible del medio biofísico y que resta sustentabilidad al proceso de desarrollo que se pretende impulsar.

Tanto los problemas ambientales como los municipales requieren, para su comprensión, de una reconstrucción de los procesos históricos que dieron origen, por una parte, a la estructuración contemporánea de los Estados latinoamericanos centralistas y, por otra, a la implementación de un cierto estilo de desarrollo, dominante en la región. Cabe insistir en el papel fundamental que en América Latina, y desde fines de la última contienda mundial, ha desempeñado el Estado como impulsor del estilo de desarrollo prevaleciente. Al carácter centralista del primero corresponde uno de los principales 
rasgos distintivos del segundo: su enfoque indiscriminador y homogeneizante. Como se ha señalado ya tantas veces, el estilo de desarrollo dominante en la región desde los años cuarenta se ha basado en patrones socioeconómicos urbano-industriales, vinculados a determinadas formas de vida propias de los estratos sociales más elevados, y a un conjunto de tecnologías, por lo general exógenas, que resultan con frecuencia inadecuadas desde el punto de vista ambiental y social. Las correspondientes estrategias productivas se han decidido en forma centralista y se han llevado a cabo sin tomar en consideración el extraordinario mosaico de situaciones ecológicas y sociales que presenta la región. Este enfoque homogeneizador desaprovecha bastantes recursos y sobreexplota muchos más.

La crisis actual, que en muchos países de la región se desencadenó por su insostenible deuda externa, pero que de ninguna manera puedé reducirse a este factor, ha implicado, en su primera fase, el agravamiento de las consecuencias negativas del estilo de desarrollo que tan someramente se acaba de caracterizar. En un aparente movimiento de "huida hacia adelante", lejos de revisar las estrategias productivas vigentes, se han redoblado esfuerzos para impulsarlas contra viento y marea. El afán de hacer "más de lo mismo" pero con mayor eficiencia, ha contribuido a profundizar la propia crisis. En este contexto habría que estudiar la inoperancia de los gobiernos locales municipales y el creciente deterioro de nuestro medio biofísico. Se trata de problemas estructurales graves que no pueden resolverse con medidas sectoriales aisladas, que actuarian como paliativos útiles, pero insuficientes. No se trata tan sólo de reforzar las finanzas municipales y la normativa anticontaminante, sino de reformar el Estado y cambiar el rumbo del proceso de desarrollo. La modernización descentralizadora y democrática del Estado sería precisamente lo que permitiría transformar el estilo de desarrollo. La necesidad de este proceso descentralizador y democrático constituye hoy el común denominador de los problemas municipales y ambientales. Sobre esta base, las propuestas que se dirijan hacia la superación de la crisis actual tendrian que incluir tanto una política ambiental que incorpore en los niveles operativos a los gobiernos locales, como una revalorización de éstos últimos como instancias promotoras de un nuevo desarrollo sustentable desde el punto de vista social y ambiental.

\section{El municipio y la descentralización}

La evolución histórica de la situación de las municipalidades latinoamericanas presenta notables coincidencias y sincronías. El pun- 
to de partida de esta evolución se ubica en la situación de los Cabildos coloniales, cajas de resonancia de los intereses de los grupos criollos en ascenso. Los Cabildos desempeñaron un papel político decisivo en los diversos procesos independentistas que, en forma casi simultánea, se desencadenaron en la región. La mayoría de las declaraciones de independencia tuvieron lugar en los Cabildos de las ciudades virreinales. Sin embargo, la consumación de la independencia y la consolidación de los nuevos Estados nacionales implicó en todos los casos el progresivo relegamiento de las municipalidades. El espacio político que ofrecían los Cabildos resultó por completo insuficiente como foro para las intensas luchas con las que los nuevos grupos emergentes se disputaban la hegemonía. Fue muy efímera o circunstancial la etapa en que parecía que los Estados latinoamericanos independientes se podían construir "de abajo hacia arriba", a partir de los gobiernos locales constituidos. Las pugnas entre federalistas y centralistas, que se sucedieron a lo largo del siglo pasado en la mayoría de los países americanos, reflejaban proyectos alternativos de nación y se desarrollaron al margen y por encima de los niveles locales de la política. En todas las latitudes del continente se asumió que un fuerte centralismo era indispensable para la consolidación de un Estado nacional. Las particularidades locales, e incluso las diversas culturas indígenas en aquellas subregiones en donde persistían, se concebian entonces como obstáculos para una unidad nacional que sólo podría basarse en un Estado fuerte y unitario, y en una sociedad civil tan homogénea como la legislación básica que se empezaba a desarrollar. Superados los momentos iniciales de confusión, el centralismo, que alcanzó límites grotescos bajo la administración colonial, acabó caracterizando también a las nuevas administraciones independientes. En aquellas circunstancias el centralismo podía resultar benéfico, además de inevitable, en la medida en que representaba la posibilidad de contrarrestar y superar los viejos cacicazgos locales, y facilitar de manera efectiva la consolidación de las nuevas naciones. Las municipalidades, que eran a la vez gérmenes potenciales de un nuevo Estado y sedes de aquellos cacicazgos tradicionales, sufrieron en todos los países de la región un proceso de marginación y deterioro que se prolonga casi hasta la actualidad. Supervisadas de cerca por "jefes políticos", manipuladas por los gobernadores, desprovistas de recursos de alguna significación, las autoridades municipales acabaron en muchos casos desempeñando un papel folklórico y en definitiva irrelevante. Fernando Viviescas (1986) se refería a los "cien años de soledad" de los municipios de Colombia, en alusión a la escasa relevancia que les conferia la centenaria Constitución vigente en su país. 
L. Ríos del Castillo (1984) señalaba que en el periodo de algo más de siglo y medio de evolución independiente del Perú, la vida municipal llegó prácticamente a extinguirse durante 27 años y sufrió durante otros 55 años la designación, por parte del poder central, de las máximas autoridades locales. La historia de las miserias municipales podría repetirse, con distintos énfasis y matices, en cada uno de los países de la región. Las municipalidades latinoamericanas han sobrevivido a duras penas, gracias a su fuerte arraigo histórico popular, a los naturales sentimientos de vecindad territorial y a la justificación implícita en la necesidad de proveer algunos servicios básicos a las comunidades locales.

En la inmediata posguerra, el persistente centralismo había agotado ya su ciclo histórico, carecía de las justificaciones que en su defensa pudieron invocarse en el transcurso del siglo pasado y constituía un poderoso factor limitante para el potencial de desarrollo de la región. Una vez consolidados los Estados nacionales, sólo hubieran podido reforzarse mediante la decidida reconstrucción y el potenciamiento de sus eslabones primarios, es decir, de los gobiernos locales municipales. Sin embargo, el auge del estilo de desarrollo homogeneizador, impulsado por el Estado centralista, canceló de momento las esperanzas de una rehabilitación de la instancia municipal y aceleró su viejo proceso de deterioro.

Esta última etapa de la marginación de las municipalidades no ha implicado grandes cambios juridicos que afecten sus límites autonómicos. La plena autonomía municipal consta de tres elementos: a) la libre elección de las principales autoridades municipales, b) la creación, recaudación, gasto e inversión de sus ingresos, c) la libre gestión de las materias de competencia local. A ellos se une el principio de que la impugnación de los actos de la municipalidad sólo es posible en los términos que la ley establezca de forma expresa. En muchos casos el marco jurídico nacional sólo prevé una autonomía municipal bastante restringida. En otros, en que una amplia autonomía tiene pleno asiento en la legislación, las circunstancias concretas se encargan de recortar de facto el ejercicio autonómico. Pero la principal limitante para el desarrollo de las municipalidades deriva de su exigua capacidad económica. Las funciones de competencia municipal aún mermadas de jure o de facto por el centralismo dominante, suelen exceder con mucho la capacidad de acción correspondiente a los estados financieros de los municipios. Con la notoria excepción de Brasil, en la mayoría de los países de la región el conjunto de las finanzas municipales representa menos de $5 \%$ de los ingresos ordinarios del Estado. En el caso de México, que es notable por la gran autonomía legal de sus ayuntamientos, este por- 
centaje llegó a ser de $1 \%$ en 1982. En casi todos los casos el ritmo de crecimiento de la hacienda pública nacional ha sido mucho mayor que el de los recursos hacendarios municipales. Los mecanismos recaudatorios de las municipalidades permanecen ajenos a la modernización del fisco nacional y suelen ser lentos y obsoletos.

La otra fuerte limitante para el desarrollo municipal radica en la escasa capacitación técnica de los recursos humanos de las municipalidades pequeñas o medianas. En bastantes paises de la región se realizan notables esfuerzos para la capacitación municipal en materia administrativa, pero los aspectos tecnológicos y de planificación suelen permanecer relegados. En virtud de sus endebles recursos económicos y de sus recursos humanos insuficientemente capacitados, las municipalidades se han visto obligadas a restringir su marco de acción, con independencia de la esfera legal de sus competencias y responsabilidades. En este sentido es notable la tendencia de las municipalidades a concentrar toda su atención en los problemas urbanos de las cabeceras, aun cuando el ámbito de la jurisdicción municipal se extienda también a un amplio territorio rural. Esta pérdida de jurisdicción municipal rural puede incluso sancionarse en el plano legal, como en el caso de Bolivia, donde el régimen municipal se circunscribe a las áreas propiamente urbanas.

Ante la creciente incapacidad de las municipalidades para garantizar la adecuada provisión de los servicios urbanos básicos, sobre todo en lo que atañe al agua potable y al alcantarillado, las administraciones centrales establecieron los llamados "entes desconcentrados" o "descentralizados". ${ }^{2}$ Su creación fue también, con frecuencia, prerrequisito para tener acceso al crédito internacional. La entrada en operación de dichos entes mermó de hecho las ya limitadas competencias municipales. Su actuación, basada en abundantes recursos técnicos, se suele limitar sin embargo a la utilización de las opciones técnicas convencionales, que resultan inadecuadas en el contexto del llamado "sector informal". Los estándares preconizados, además de poco realistas, son impuestos de manera homogénea en las diversas situaciones ambientales y socioculturales de cada país. Se hace patente así la orientación centralista de los entes descentralizados, pesados aparatos tecnoburocráticos cuya orientación y control resulta difícil incluso para las administracio-

' A titulo de ejemplos: Corporación de Aguas Potables y Alcantarillado (CORP $\mathrm{A}$. ( $\mathrm{U}$ AS) de Bolivia; el lnstituto Nacional de Aguas Potables y Alcantarillado (INAPA) de República Dominicana; la Administración Nacional de Aguas (ANDA) de El Salvador; el Instituto Nacional de Obras Sanitarias (wos), de Venezuela. 
nes centrales que los crearon, ni se diga para las municipalidades en cuya demarcación actúan.

Otro factor que en ocasiones ha podido agravar la situación municipal consiste en el intercalamiento - entre los gobiernos locales y el gobierno nacional- de nuevas instancias intermedias que se agregan a aquellas, tradicionales, (Estados federativos, Provincias, etc.), que fueron objeto de intensas polémicas en las primeras etapas constitutivas del Estado. Ejemplo de estas nuevas instancias intermedias serían las Corporaciones regionales de desarrollo. Su articulación en la estructura del Estado presenta dificultades políticojurídicas, pero los recursos puestos a su disposición suelen ser abundantes, muy superiores desde luego a aquéllos a los que tienen acceso los gobiernos locales. La aparición de las corporaciones obliga a complicados ejercicios de concertación en los cuales las municipalidades suelen participar en inferioridad de condiciones.

En los últimos cuarenta años, la región ha experimentado un gran desequilibrio en su sistema de asentamientos humanos y, en especial, un crecimiento sin precedentes históricos de las tasas de urbanización. Este proceso ha planteado requerimientos extraordinarios a las instancias municipales, precisamente cuando estas últimas manifestaban un mayor grado de desgaste. Los problemas se agravaron sobre todo en las grandes áreas metropolitanas, que han actuado como polos de atracción poblacional y receptáculos de los contingentes humanos expulsados del campo por la crisis agricola concomitante con el auge del modelo urbano-industrial de desarro11o. Los problemas que implica la urbanización acelerada no siempre se plantearon en el marco de las municipalidades. Por ejemplo, el Distrito Federal de la ciudad de México había quedado privado de su régimen municipal desde 1928. En otros casos, como en Bogotá o en Caracas, las grandes ciudades conservaban sus gobiernos locales municipales, aunque limitados e intervenidos en alguna medida por el poder central. En relación con su estructura políticoadministrativa local, las grandes ciudades, y con mayor razón las áreas metropolitanas latinoamericanas, presentan a la vez problemas de centralización y de descentralización. Por una parte, el área urbana construida constituye una totalidad, un sistema unitario desde el punto de vista funcional, que exige una planificación integrada. Sin embargo, este sistema urbano, en su desbordante crecimiento, dejó muy atrás a las estructuras político-administrativas locales, de tal suerte que no corresponden ya a la nueva realidad territorial urbana. Es paradigmático el caso de los municipios rurales aledaños a los viejos nucleos urbanos: la ciudad se desbordó y los engulló, sin que tuvieran ocasión de adaptarse a la problemática que se les 
venía encima. El sistema de los gobiernos locales de las actuales áreas metropolitanas ha quedado así rebasado por la dinámica del crecimiento urbano. Resulta muy difícil coordinar a las instancias locales existentes, en función de una política urbana unitaria. Por otra parte, la realidad socioespacial que corresponde a cada uno de los entes político-administrativos locales, es todavía demasiado grande como para poder garantizar una comunicación fluida entre el gobierno locàl y la ciudadanía, y un adecuado nivel de participación de esta última en los asuntos de competencia municipal. Estas condiciones propician el desinterés por parte de la sociedad civil y el clientelismo y la tecnocracia por parte de las instancias políticas locales. El clientelismo, en particular, constituye hoy una verdadera plaga de las administraciones públicas municipales latinoamericanas.

La situación descrita se agudizó en las últimas dos décadas, durante las cuales se produjo una verdadera crisis urbana, tanto en las áreas metropolitanas como en las ciudades de orden intermedio. Se hizo patente entonces el agotamiento del peculiar modelo urbanoindustrial de desarrollo asumido. No se trata sólo de un problema de acumulación de déficits de servicios; la propia conveniencia y viabilidad de las grandes concentraciones urbanas quedó en entredicho en función de los gravísimos problemas ambientales que aquéllas generan. Las grandes ciudades representan a la vez ámbitos que ofrecen oportunidades de vida cualitativamente superiores y enormes parásitos sin control de esfinteres. En cierto sentido, esta crisis urbana que se inicia en los años sesenta fue el heraldo que anunciaba la crisis global de los años ochenta.

Ante la debilidad e ineficacia de los gobiernos locales y la inexistencia de canales apropiados para la participación de los sectores más activos de las colectividades urbanas, surgieron, sobre todo en la década pasada, movimientos sociales de nuevo cuño cuya interpretación ha representado un reto para los paradigmas sociológicos vigentes. Estos movimientos sociales urbanos (MSU) se han caracterizado por su heterogeneidad interna, su fuerte sentido territorial y su habitual independencia respecto a las organizaciones partidarias establecidas. Entre las reivindicaciones de los nis han aparecido con frecuencia creciente aquéllas de indole ambiental. La aparición de los MSU y la ausencia de interlocutores válidos en los niveles locales puso en evidencia la proximidad de la ruptura de la articulación entre el Estado y la sociedad civil. La crisis urbana municipal puso de manifiesto las limitaciones finales del modelo centralista del Estado y la disfuncionalidad de su estructura. Aparecen entonces, incluso desde los centros establecidos del poder, sugerencias 
descentralizadoras más o menos tímidas e intentos de reforma de las administraciones públicas. El municipalismo latinoamericano se encuentra así frente a una nueva oportunidad histórica, que desaprovecharía si se limitase a la defensa romántica de una venerable institución venida a menos. El reforzamiento del municipio, como instancia privilegiada de contacto entre la sociedad civil y el Estado, sólo adquiere pleno sentido en el marco de la reestructuración global de este último. El nuevo planteamiento municipalista tendría que trascender la simple reivindicación de mayor autonomía, mayores recursos y mayores competencias, para asumir el nuevo papel que le correspondería al municipio en el proceso descentralizador, como instancia promotora del desarrollo a nivel local. Para asumir esta nueva función, las municipalidades tendrían que prestar una atención muy especial al sustrato medioambiental local que hace posible cualquier proceso de desarrollo. Además de garantizar la sustentabilidad del desarrollo, el control del medio ambiente local permitiría a las municipalidades tener plena injerencia en los asuntos relativos a la calidad de vida de la colectividad territorial. El potencial de acción municipal en relación con los problemas ambientales se examinará más adelante. El fortalecimiento de los municipios no se plantea sin embargo en términos de la política ambiental, sino de la política a secas.

La situación concreta de las municipalidades latinoamericanas presenta hoy una enorme diversidad, resultado de evoluciones históricas divergentes. Se detectan al respecto tanto similaridades formales ficticias - que encubren una heterogeneidad de situaciones reales-, como el fenómeno inverso, es decir, disparidades aparentes o institucionales - que ocultan una verdadera comunidad de situaciones e intereses. El primer caso se verifica cuando, en un mismo pais, un sistema normativo único trata de englobar situaciones municipales muy variadas. La heterogeneidad municipal se puede verificar tanto en el nivel nacional como en el internacional. En México existen municipios cuya extensión es mayor que la de algunos países centroamericanos, como el de Ensenada, Baja California Norte, con $54,256 \mathrm{~km}^{2}$. El record nacional del minifundismo municipal quizás corresponda al municipio de San José Estancia Grande, Oaxaca, con $0.03 \mathrm{~km}^{2}$ de superficie. Es difícil imaginar de qué pudieran conversar el presidente municipal de Magdalena Jicotlán, Oaxaca, (224 habitantes en el Censo de 1980) y el de ciudad Nezahualcóyotl, en la que residen más de dos millones de habitantes, aunque la normatividad por la que se rijan sea la misma en ambos casos. Por otra parte, cuando se plantean comparaciones internacionales, suele ocurrir que por debajo del enorme abanico de disposiciones legales, po- 
líticas y administrativas se manifiestan situaciones problemáticas muy semejantes. Hasta ahora, el municipalismo latinoamericano ha producido sobre todo especialistas en cada uno de los casos nacionales, siendo muy escasos los esfuerzos por elaborar un pensamiento común basado en comparaciones internacionales. En este sentido, no ayuda mucho la variedad terminológica existente: municipios, ayuntamientos, cantones, municipalidades, distritos, parroquias; son conceptos que no significan lo mismo en los diferentes contextos nacionales de la región. Quizá lo importante sea evitar en cada caso la confusión entre una realidad social y espacial concreta, de carácter local (en México: el "municipio"), y la instancia políticoadministrativa correspondiente (en México: el "ayuntamiento"). Por encima de las diferencias institucionales, urge en la región un esfuerzo clasificador común, sobre bases comparativas sólidas. Para contribuir a este esfuerzo, se anexan unos cuadros en los que se ha vertido la información disponible acerca de la situación institucional de las municipalidades en nueve países de la región. ${ }^{3}$

\section{El pensamiento ambientalista y la descentralización}

Si bien el deterioro del medio ambiente constituye en América Latina un proceso antiguo, con frecuentes raices coloniales, el agravamiento que ha determinado la actual toma de conciencia, pública y privada, es en cambio bastante reciente, habiéndose producido sobre todo en las últimas cuatro décadas. En este periodo reciente, el medio ambiente regional ha sufrido transformaciones mucho más intensas que en toda su historia anterior, y con frecuencia irreversibles. La reacción oficial frente al problema fue, por otra parte, bastante tardía. La cuestión ambiental se tornó objeto de preocupación para las administraciones públicas de la región, sobre todo a partir de los preparativos de la Conferencia sobre el Medio Humano, celebrada en Estocolmo en 1972. El "espíritu de Estocolmo" tiene un significado distinto según se trate de los países industrializados que promovieron la Conferencia, o de los países en desarrollo que acudieron a la misma con recelos poco disimulados. En el primer caso, se trataba de abrir un foro en el que pudieran debatirse asuntos ambientales de alcance global, que no pudieran manejarse por medio de una normatividad ya bastante desarrollada a nivel nacional. El

\footnotetext{
'Estos cuadros se incluveron en el trabajo patrocinado por pixin y mencionado en la nota 1 . Se agradece al iNL'N su disposición para su reproducción en este articulo. Como antecedente de estos cuadros, cabria citar aquellos publicados en Camacho et al./sIap (1985).
} 


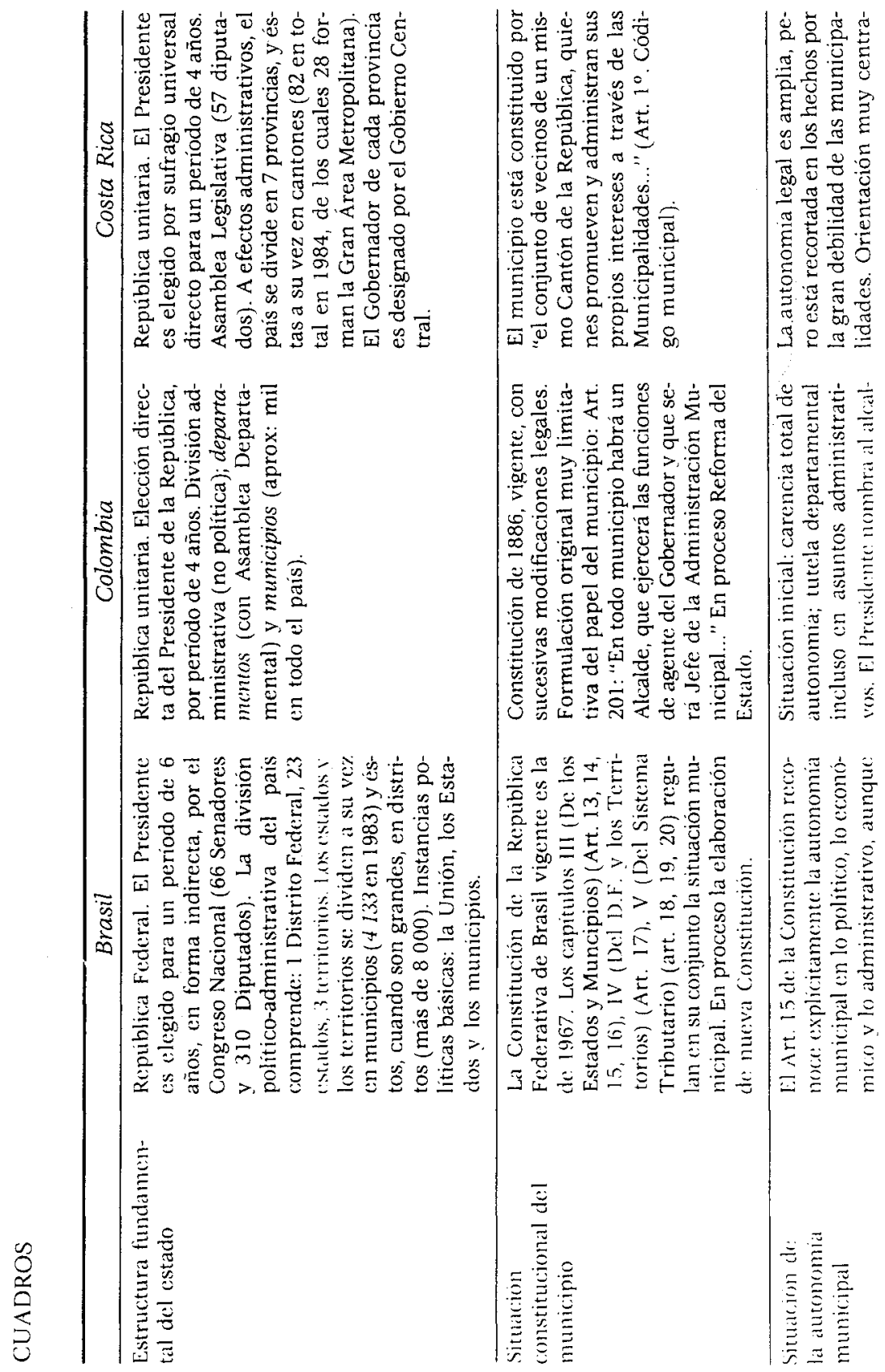




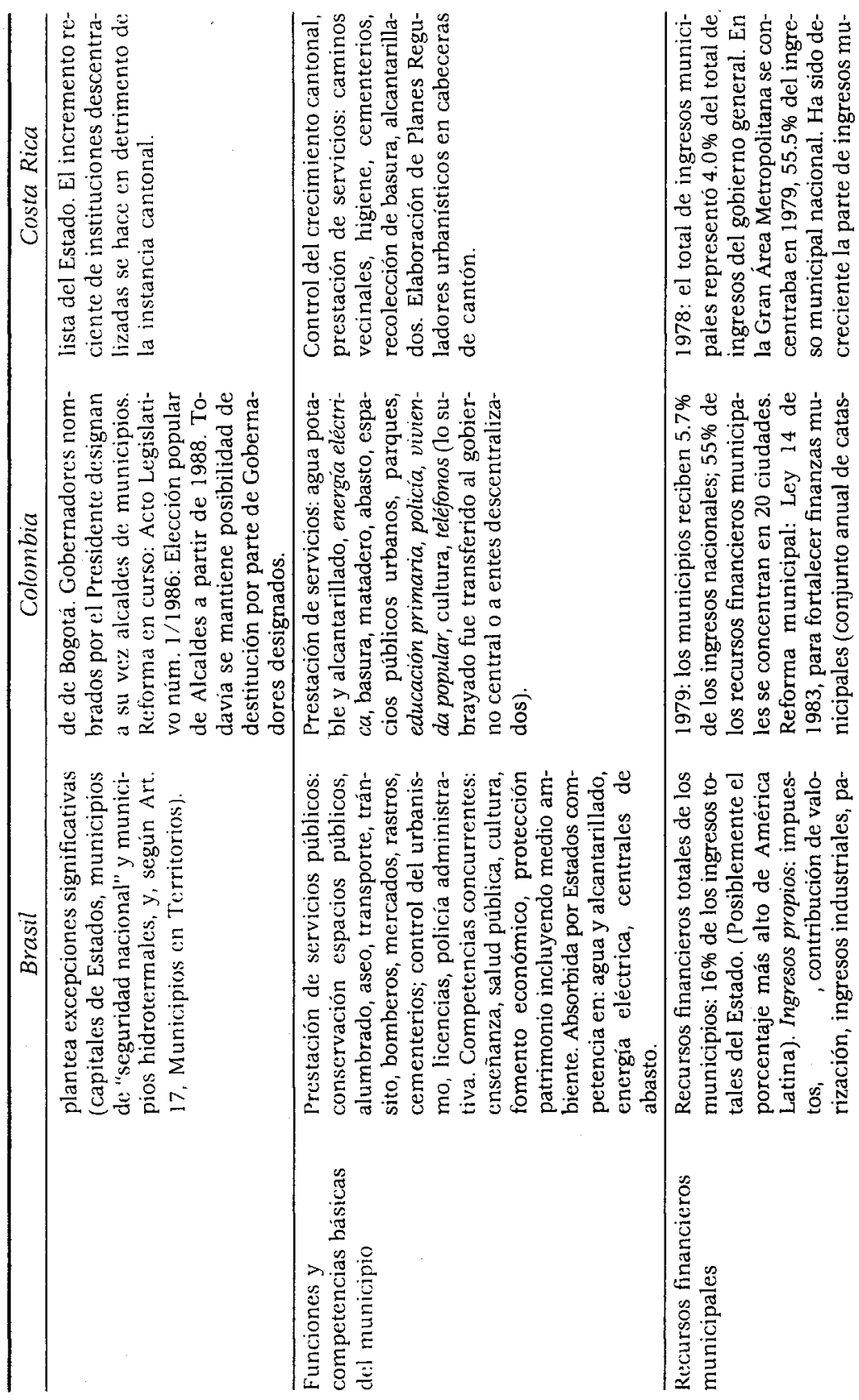




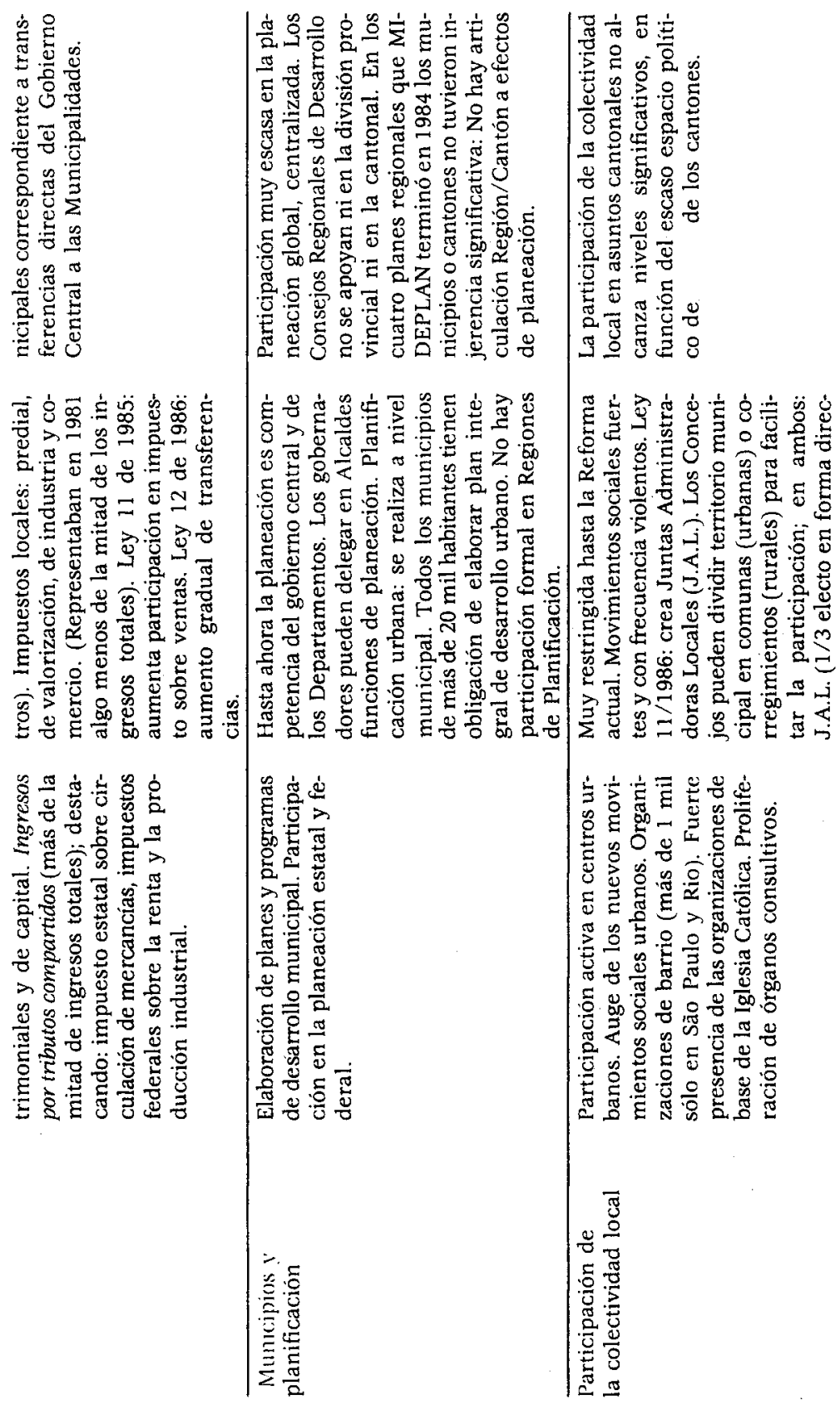




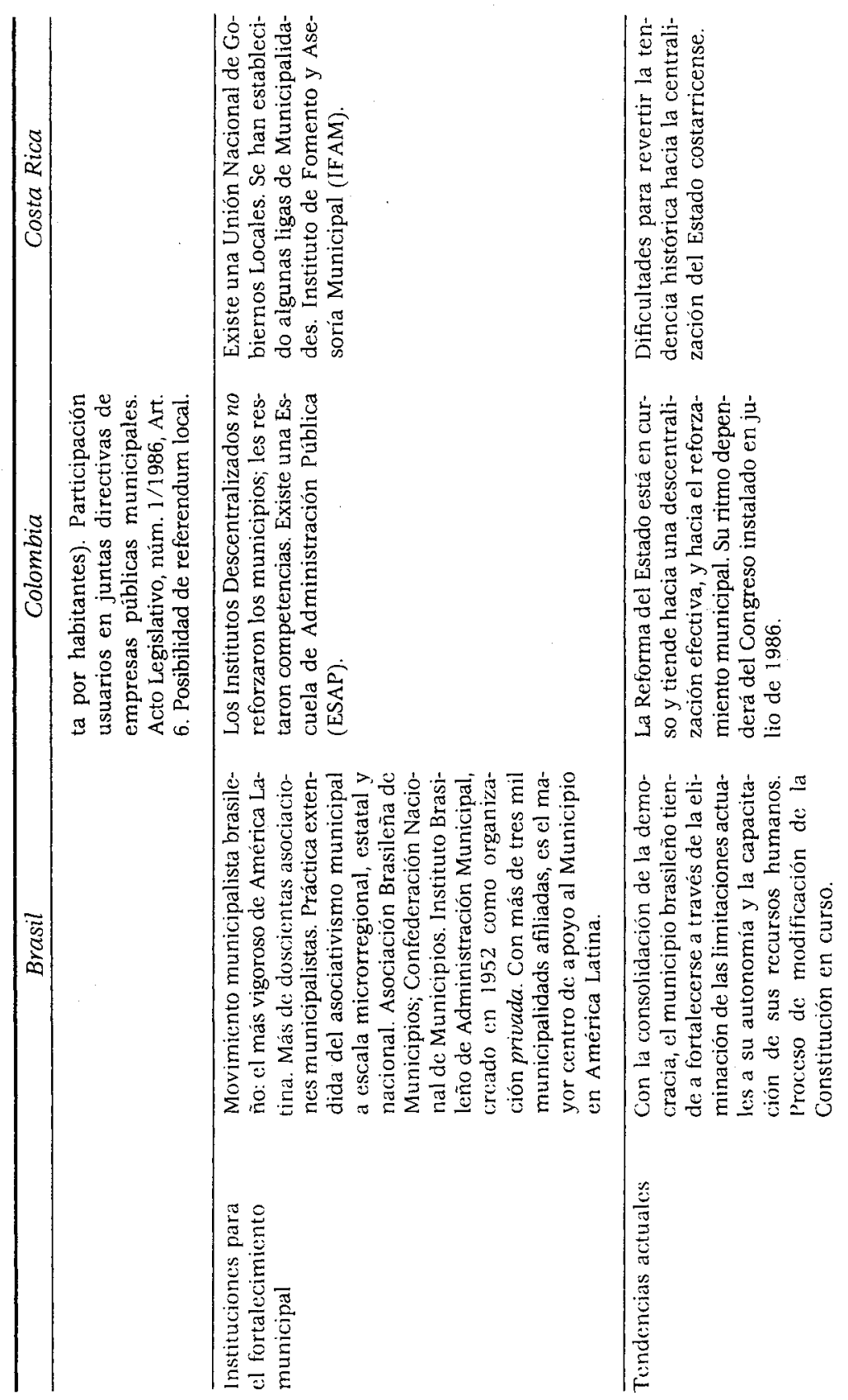




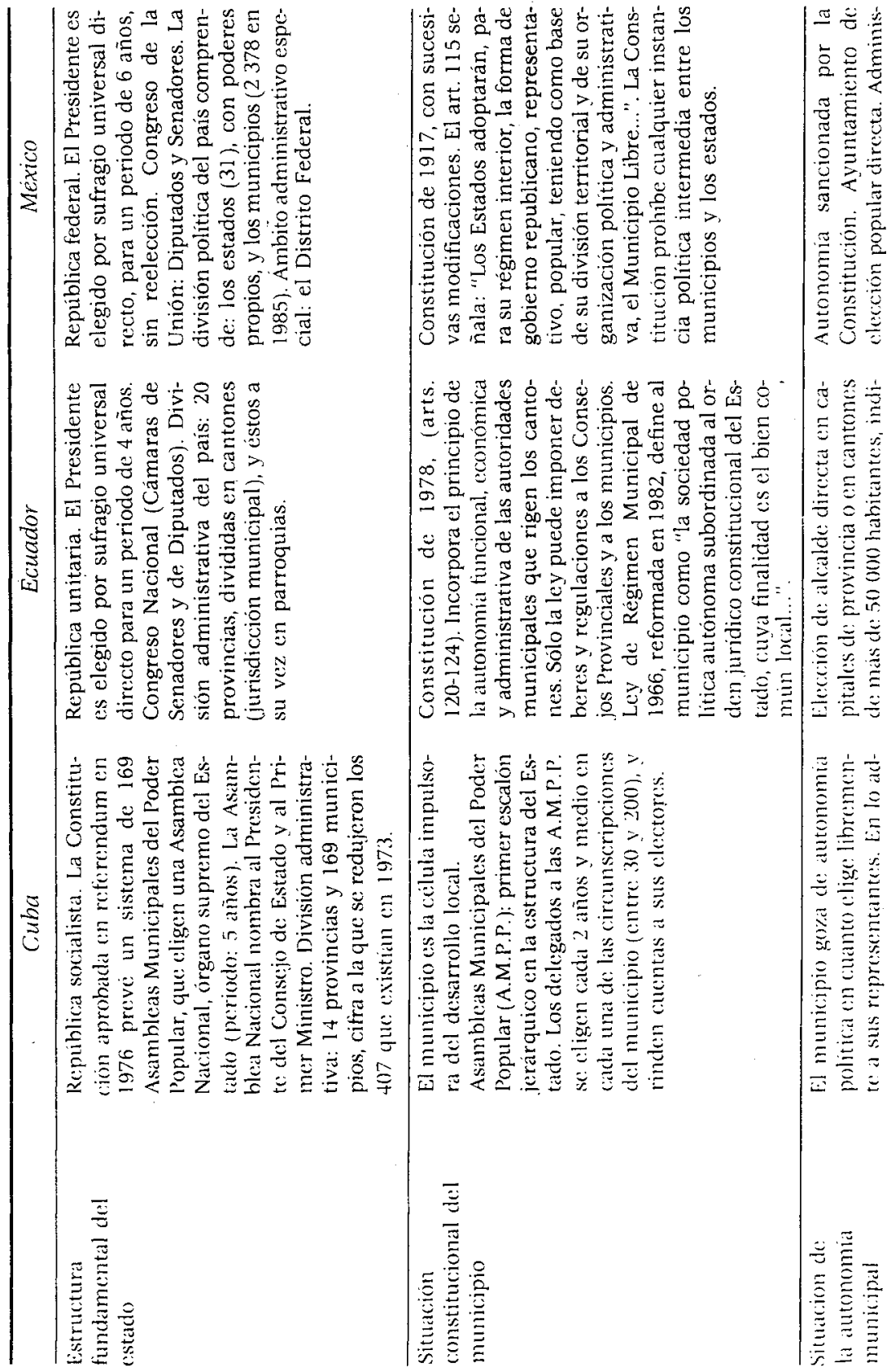




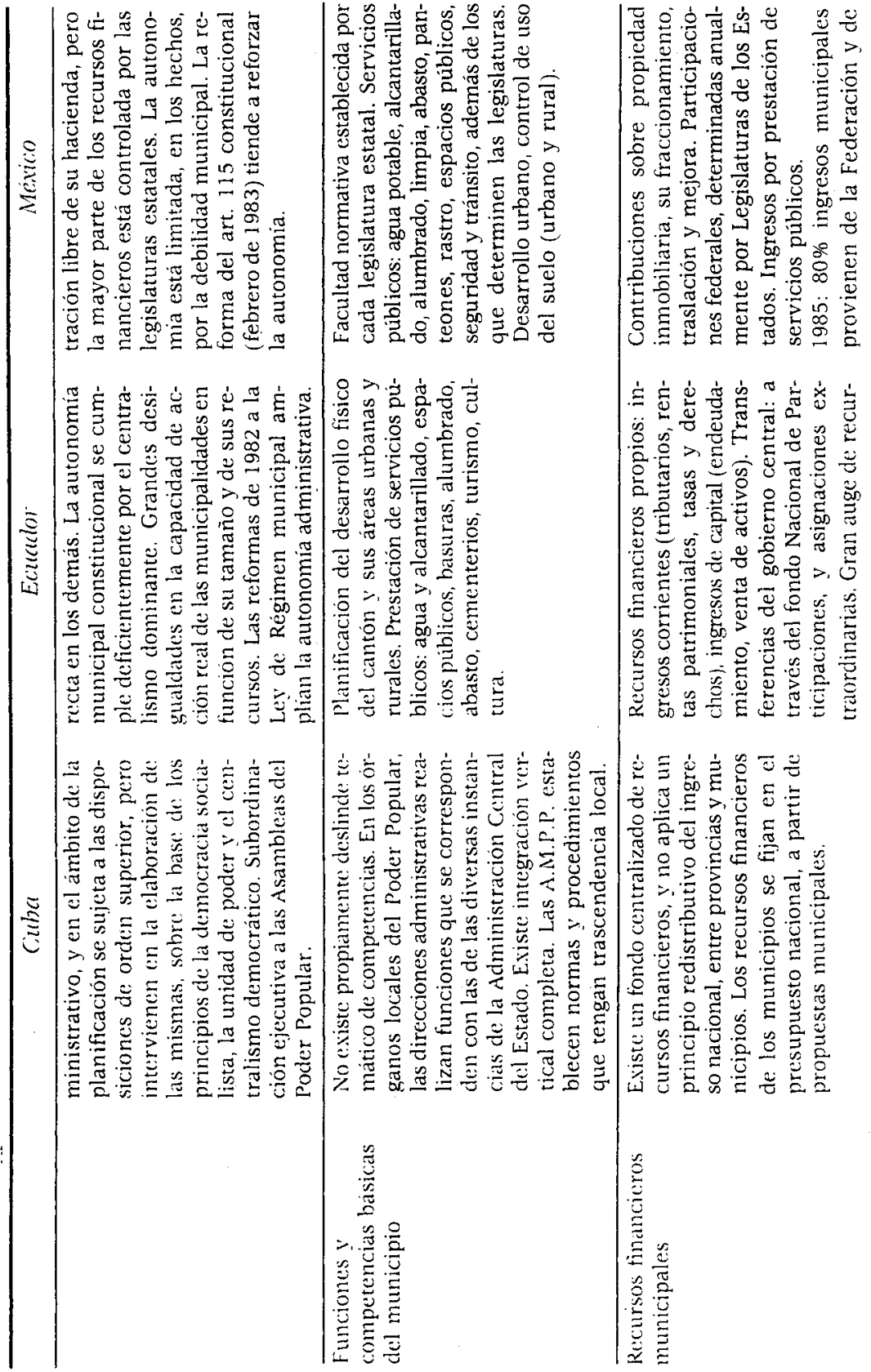




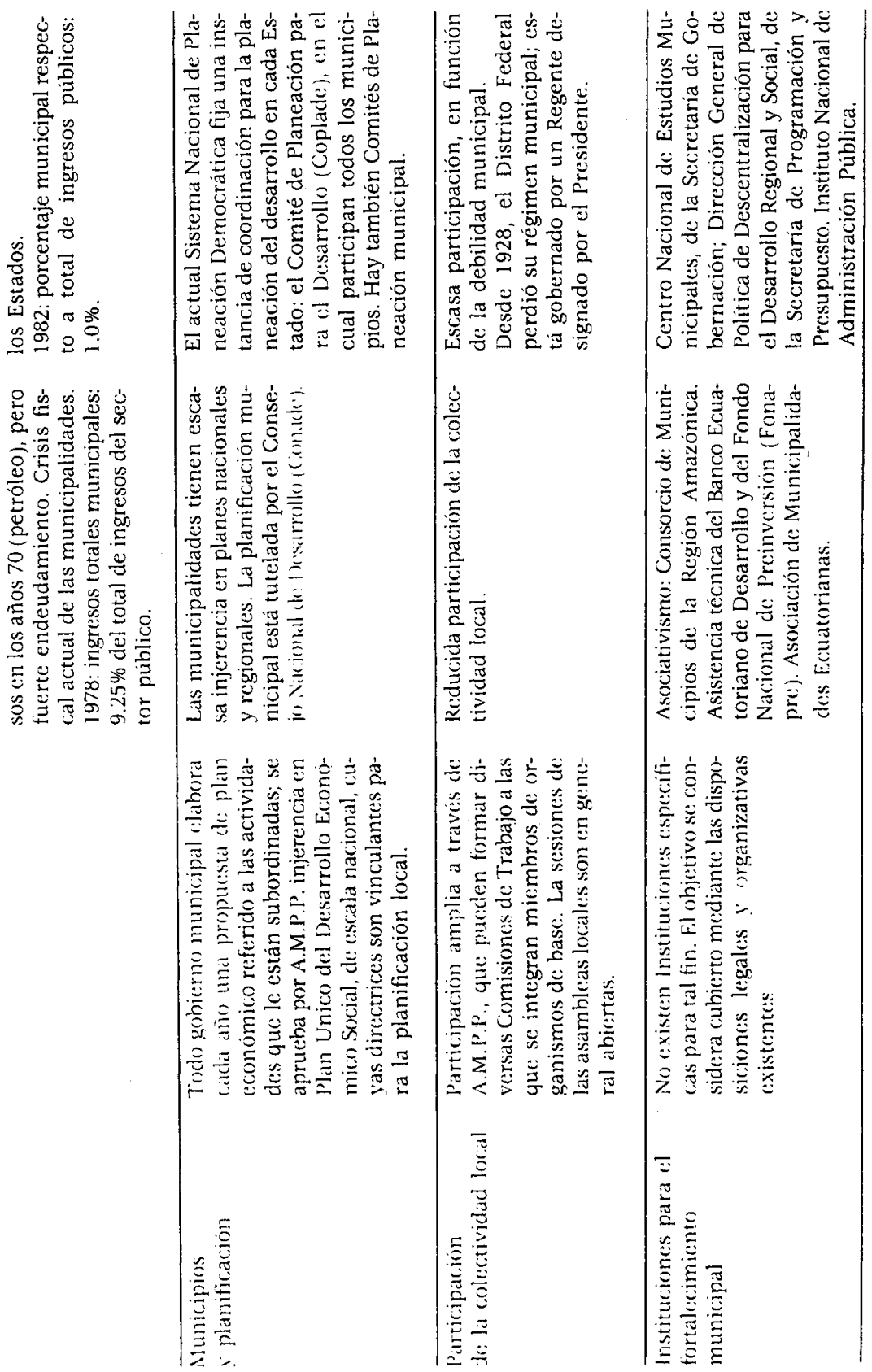




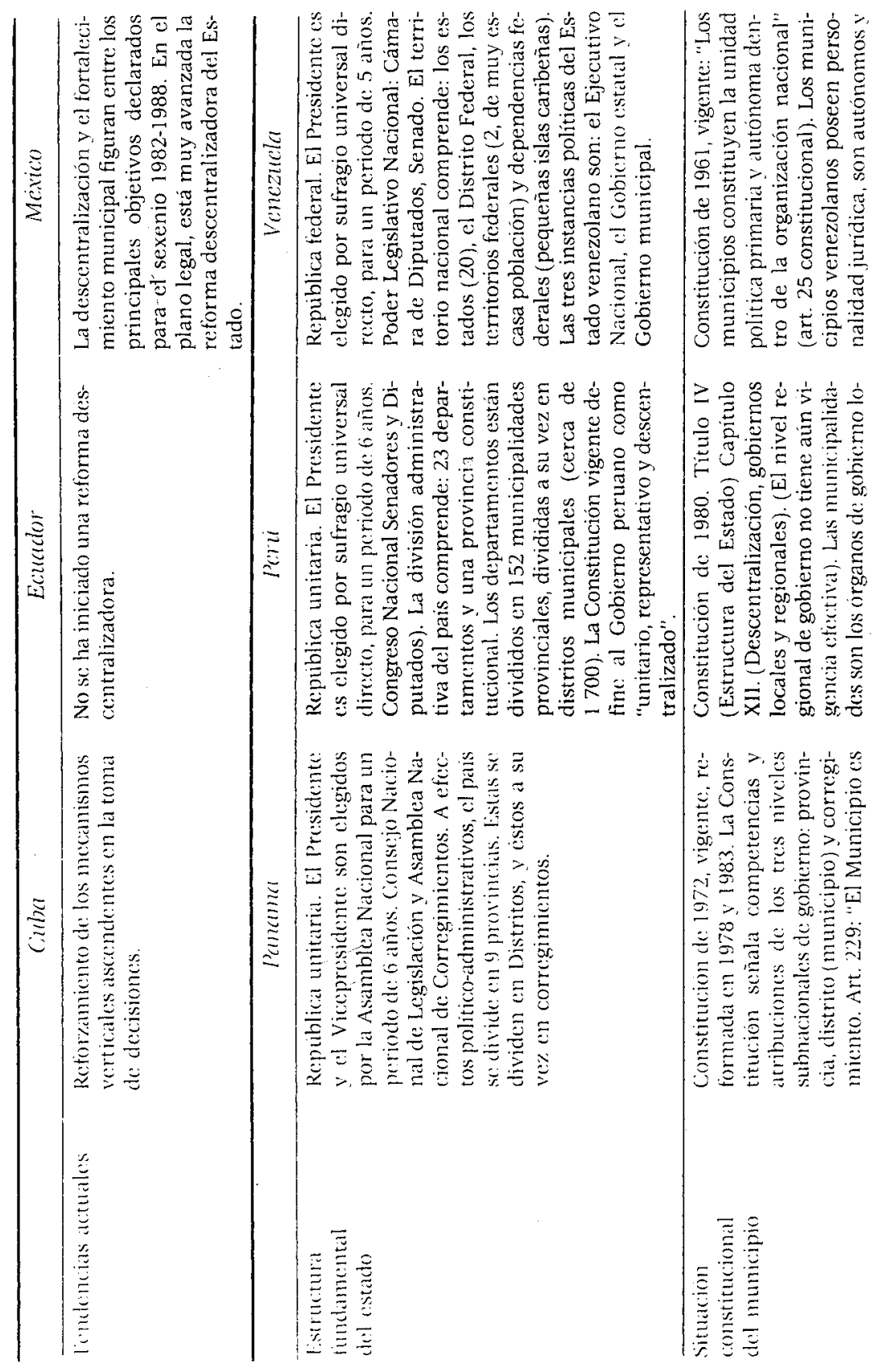



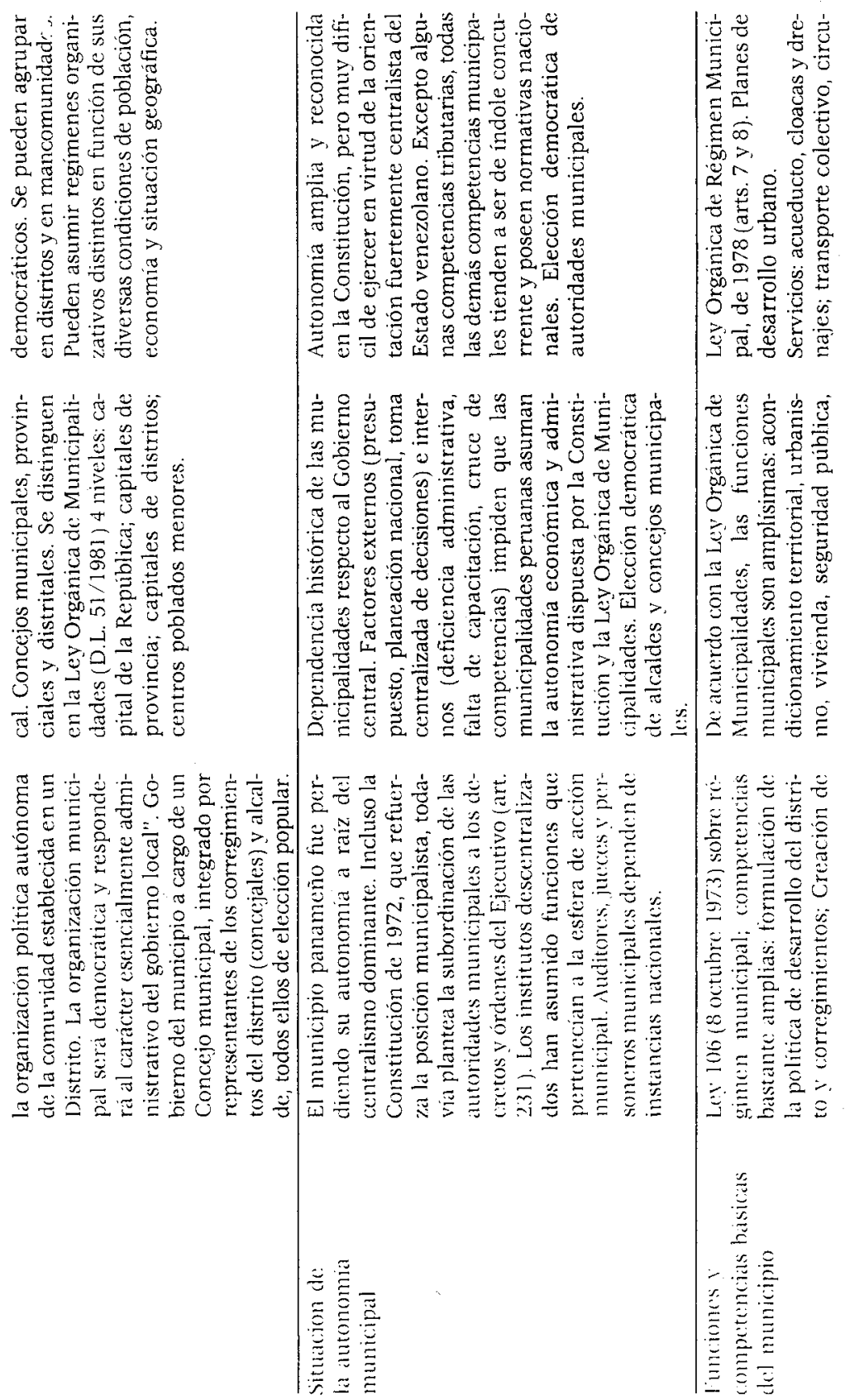

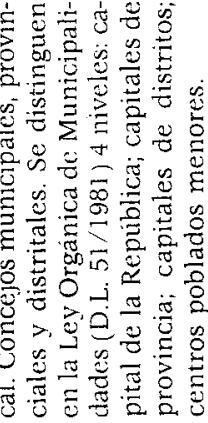

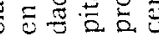

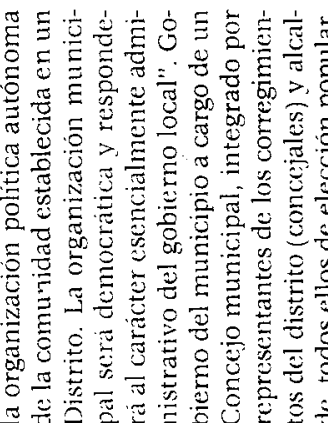

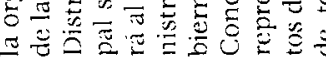




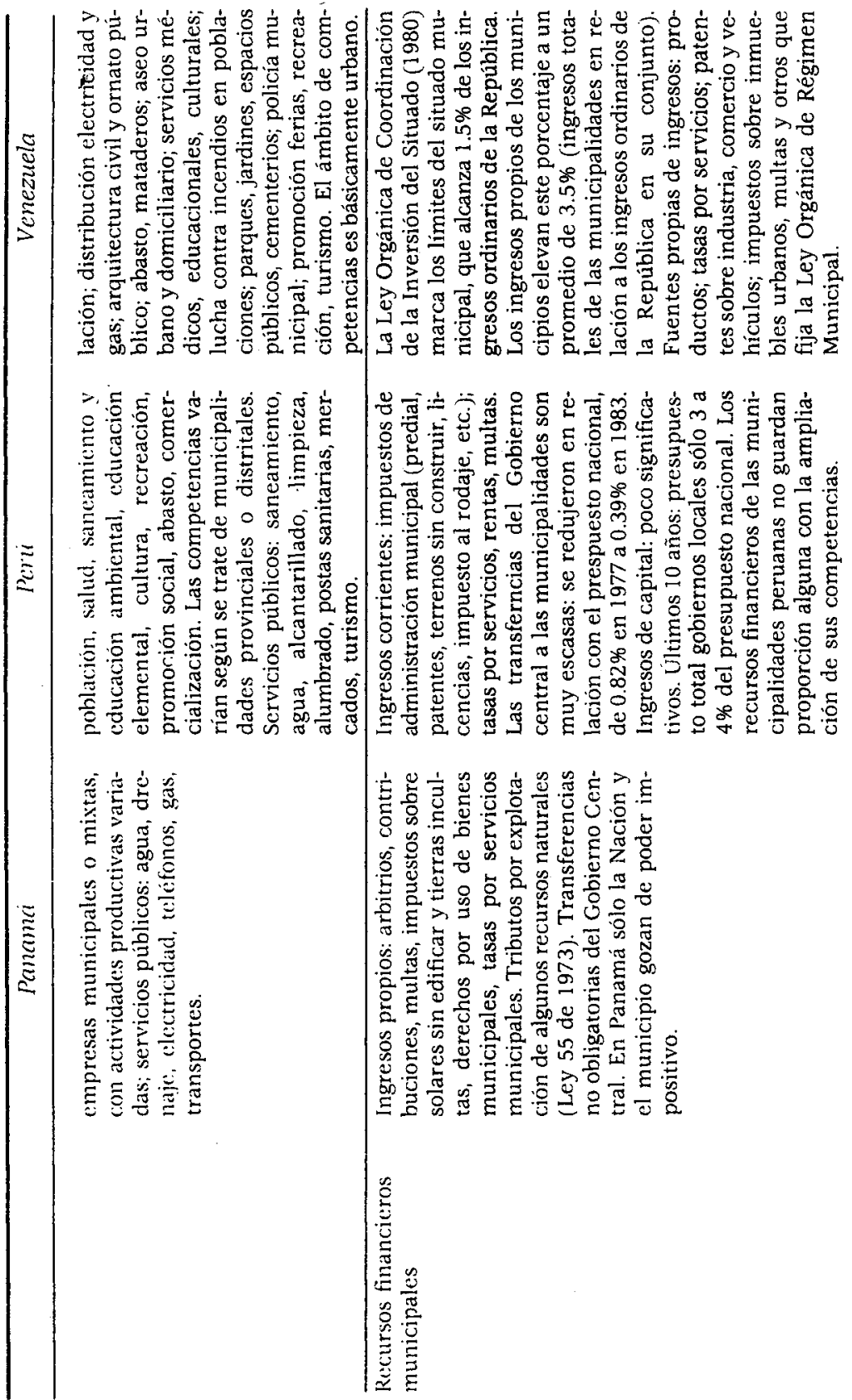




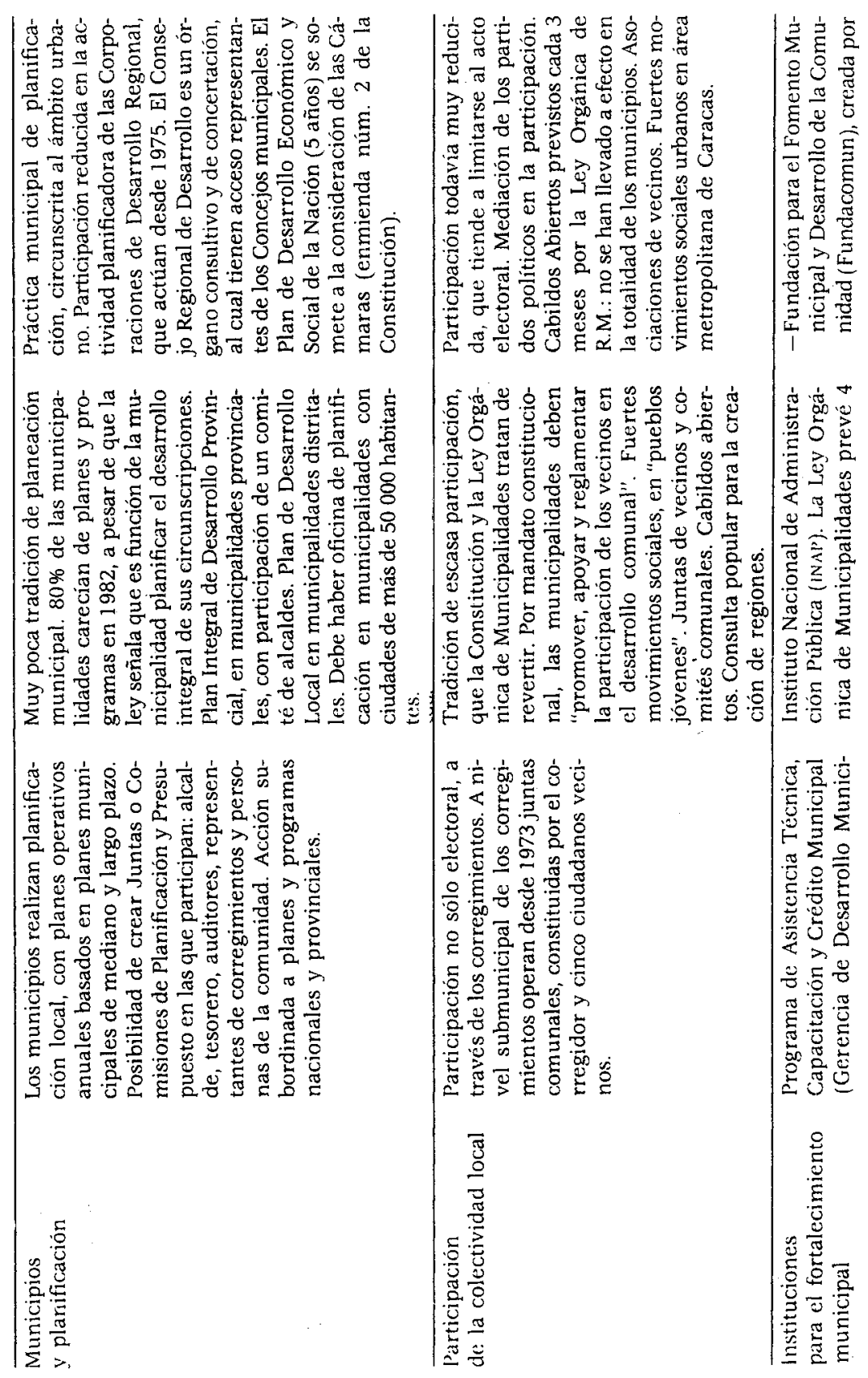




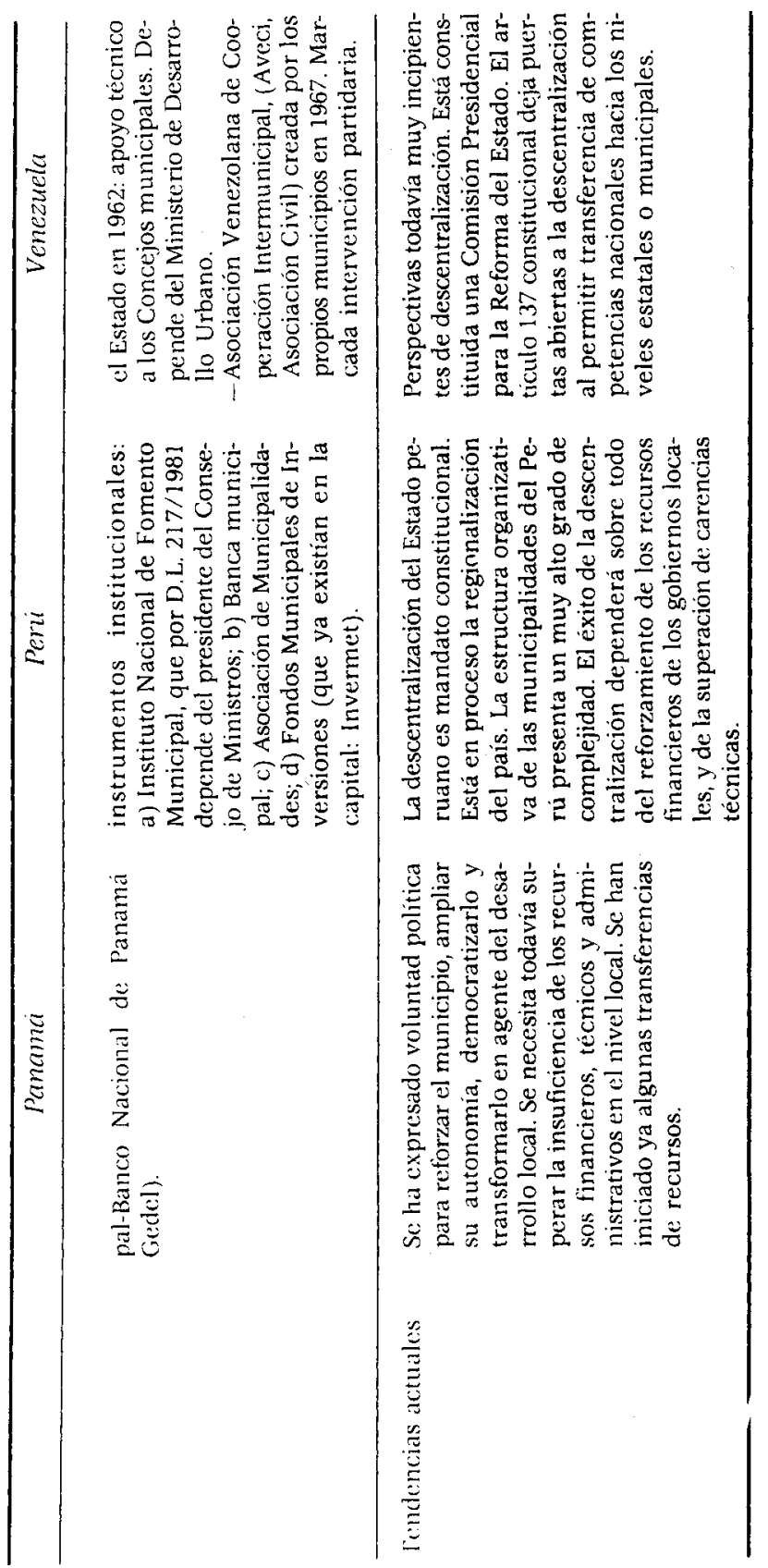


ejemplo típico de los asuntos de esta índole podría hallarse en la llamada "lluvia ácida", producto de una interacción entre las emisiones de las áreas industriales y la humedad atmosférica, que los vientos se encargan de democratizar sin respeto alguno por las fronteras nacionales. Los países menos industrializados, en cambio, vieron en la Conferencia la oportunidad de vincular la cuestión ambiental con la del desarrollo nacional, asumido como objetivo irrenunciable. Apenas se empezaba entonces a comprender la gravedad de los procesos ambientales en curso, pero se tomó conciencia de que sólo podrian enfocarse desde la perspectiva de la atención a las necesidades ineludibles del desarrollo. Sobre esta base comenzó a gestarse un pensamiento ambientalista propio de la región, más orientado hacia el manejo integrado de los recursos que hacia la resolución de problemas específicos como los que plantean las contaminaciones de diversa índole. El ambientalismo latinoamericano se alejaba así tanto de las posiciones conservacionistas como de las desarrollistas a ultranza. Sus tesis principales han recibido ya suficiente difusión, por lo que bastará aquí recordar la correlación causal que plantea entre el deterioro ambiental y el estilo de desarrollo que predomina en la región, la insistencia en el carácter transectorial de los problemas del medio ambiente, la prioridad conferida al mejoramiento de? la calidad de vida y a la satisfacción de las "necesidades básicas" de la población mayoritaria, como objetivos de un auténtico proceso de desarrollo. A pesar de que las reivindicaciones de tipo ambiental hicieron también su aparición en los ya citados movimientos sociales urbanos, pareceria que en la región los planteamientos ambientalistas se abrieron camino "de arriba hacia abajo", promovidos por algunos funcionarios ilustrados que les dieron cabida entre las preocupaciones de la administración pública, sin que todavía se vieran forzados a ello por una presión ciudadana que apenas comenzaba a tomar cuerpo en ciertos estratos sociales urbanos. No fue fácil la difusión y consolidación de las posiciones ambientalistas, que se enfrentaron a todo tipo de obstáculos. En el orden conceptual, el ambientalismo arrastraba todas las dificultades propias de la transdisciplinariedad de los problemas socio-ambientales. La relccion cntre: la sociedad y la naturaleza no aparecía como objeto en ninguno de: los paradigmas disciplinarios establecidos, respetuosos del vicjo corte entre las "ciencias del espíritu" y las "naturales". Estos paradigmas profesionales establecidos eran - y son - incapaces de asimilar por si mismos una problemática ajena a las que les dieron origen, y culya atención pondría en cuestionamiento una buena parte: de las practicas sociales vigentes. Nada hay menos "ambicntalista" que la formación tradicional de los ingenieros civiles, de los agronomos, de: los economistas, o de los sociólogos, por sólo mencionar algumas de: 
las profesiones que pudieran referirse a la relación sociedad/medio ambiente. En el plano político-administrativo, el principio de la intersectorialidad chocaba de frente con la habitual organización sectorizada del Estado. Por otra parte, las premuras de los tiempos politicos de acción congeniaban difícilmente con los extendidos plazos en que se desarrollan muchos de los procesos naturales. A un político agobiado por la crisis, la amenaza de una salinización vista a cincuenta años podría causarle hilaridad.

Los obstáculos mencionados no impidieron que la causa ambientalista registrara en la región avances notables, sobre todo en los últimos diez años. En el plano jurídico, se han desarrollado esfuerzos para unificar y dar coherencia a la normatividad ambiental, que con anterioridad a la década de los años setenta era insuficiente, dispersa e incluso con frecuencia contradictoria. El "Código Nacional de los Recursos Naturales Renovables y de Protección al Medio Ambiente" de Colombia (1974) y la "Ley Orgánica del Ambiente", de Venezuela (1976), significaron en su momento importantes pasos iniciales en el proceso unificador de las legislaciones respectivas. Este proceso muestra hoy en América Latina grados de avance muy dispares. En el marco de las administraciones públicas, se constituyeron instancias para la atención especifica de los problemas ambientales. Exceptuando el caso de Venezuela, la jerarquía de estas instancias no correspondió al nivel de un Ministerio o Secretaría de Estado. Además, quedó sin resolver el conflicto de la ubicación sectorizada de un problema transectorial, como lo es el ambiental. Las instancias a cargo del medio ambiente nunca tuvieron poder suficiente para enfrentar en toda su complejidad la problemática de la que supuestamente se ocupaban. Se perfiló entonces la solución que consiste en crear nuevas instancias de concertación intersectorial, bajo supervisión directa de la Presidencia de la República, y en estrecho contacto con el organismo encargado de la planificación nacional. De esta forma se procedió en México, cuando se creó, en 1985, la Comisión Nacional de Ecología.

La cooperación internacional también ha registrado avances en la región; para impulsarla se han celebrado cinco Reuniones Regionales Intergubernamentales sobre Medio Ambiente, la última de ellas en Montevideo, abril de 1987. En lo que atañe a la sociedad civil, los movimientos ecologistas latinoamericanos carecen todavia del vigor y de la presencia política de sus homólogos de los países industrializados, pero han logrado un fuerte impulso en los últimos años, se han consolidado como interlocutores ineludibles de las diversas instancias de gobierno, y están desempeñando un papel creciente en la toma de conciencia ambiental por parte de las comuni- 
dades. Las posiciones estrictamente conservacionistas mantienen todavia una fuerte presencia entre los ecologistas de la región.

A pesar de los avances mencionados, puede afirmarse que la dimensión ambiental todavía no ha encontrado en las sociedades latinoamericanas un espacio político a la escala de los problemas a enfrentar. La actual gran crisis de los años ochenta sorprendió a las posiciones ambientalistas en una fase incipiente de institucionalización, e implicó inicialmente un grave retroceso para la causa del medio ambiente y del desarrollo sostenible. La crisis del estilo de desarrollo dominante, que el movimiento ambientalista latinoamericano venía anunciando desde tiempo atrás, no se precipitó por razones ambientales. Los factores desencadenantes, ya que no sus causas, han sido más bien el abultado servicio de la deuda y el dramático deterioro de los términos de intercambio económico de la región con los países industrializados. Se trata pues de factores que parecen encajar todavía en el paradigma de los economistas. Como ya se indicó, la respuesta inmediata a la crisis consistió en redoblar esfuerzos para impulsar las mismas estrategias productivas que le habían dado origen. En esta etapa inicial, la atención a la dinámica del medio ambiente pareció descender en la escala de prioridades gubernamentales. Las medidas de emergencia se basaron en consideraciones de corto plazo, y determinaron una mayor presión sobre los recursos naturales, así como un mayor deterioro ambiental. Por lo general, se tradujeron en una reactivación del modelo primario-exportador, por medio de la cual se trataba de compensar el descenso de precios internacionales con una mayor producción. Tampoco estuvo ausente el fantasma del neoliberalismo conservador, amagado tras las medidas antiestatistas y reprivatizadoras. Ante una opinión pública cada vez más alerta, los gobiernos de la región tuvieron que vencer la tentación de retirarse de las tareas de control ambiental y reconocieron los limites del "laissez-faire". Conviene no olvidar que los países industrializados que con mayor énfasis predican hoy el dogma neoliberal y las virtudes de la des-regulación, son precisamente aquellos que mayor impulso han dado a la intervención del Estado para la defensa, el control y el mejoramiento de su propio medio ambiente.

Las dificultades que todavía persisten para superar la fase aguda de la crisis han tenido la virtud de resignar a los gobiernos a una búsqueda de "grandes remedios". Ahora que ya sabemos que de esta crisis no se sale simplemente "redoblando esfuerzos", se oye hablar cada vez más de "cambios estructurales" -aunque no se precise demasiado en qué puedan consistir-y de nuevos procesos para un desarrollo sustentable, es decir, sano desde el punto de vista eco- 
lógico. Tras su marginación inicial, la consideración ambiental empieza a reasumir un papel importante. Podría representar un signo prometedor la celebración de reuniones como la Primera Conferencia Interparlamentaria sobre el Medio Ambiente en América Latina y el Caribe (México, marzo de 1987), en las que los poderes públicos de la región han declarado otorgar primera prioridad a la atención a la cuestión ambiental.

Por su parte, los planteamientos ambientalistas tampoco están saliendo incólumes de la crisis. Los ambientalistas necesitan sacudir su imagen de coro de plañideras y poner a trabajar su imaginación para la formulación de opciones realistas. Se enfrentan así al reto de alcanzar una operatividad de la cual han carecido mientras se han mantenido en un plano testimonial y de denuncia. "Está bien, tienen razón", les dicen algunos políticos; "las estrategias productivas a las que se ha dado impulso en las últimas décadas han resultado desastrosas para el medio ambiente. ¿Qué hubieran hecho ustedes, y qué proponen que se pudiera hacer todavia?". Frente a demandas tan alevosas, el pensamiento ambientalista está procediendo a una revisión de sus propios planteamientos, no exenta de ribetes autocríticos. Parece necesario rectificar aquellos planteamientos y formas de encarar los problemas del medio ambiente que adolecen de falta de efectividad, y que pudiéramos clasificar en los siguientes rubros: aspectos conceptuales, enfoque de la política ambiental, perspectiva temporal, escalas de intervención.

\section{a) Aspectos conceptuales}

Se compromete la validez operativa del conce pto mismo de "medio ambiente", cuando se ensancha su contenido para abarcar un conjunto heterogéneo de realidades físicas, biológicas y socioculturales. Todos estamos de acuerdo en que la realidad ambiental exige un abordamiento transdisciplinario, pero no parece que la adopción de un concepto omnibus, casi imposible de traducir a categorías operacionales, lo vaya a facilitar. La interdisciplina no se resuelve con recursos verbales; exige un enfoque sistémico, a la vez estructural y procesual, que facilite la comprensión de las articulaciones de los diferentes elementos que integran el problema, que obedecen a mecanismo causales diversos. No es mezclando semánticamente los elementos de índole social con los de naturaleza biofísica como podremos aclarar las articulaciones pertinentes; el análisis de sus interrelaciones concretas pasa por el reconocimiento de sus especificidades. Una teoría de sistemas complejos heterogéneos, cuya consolidación es cada vez más urgente, permitiría definir los instrumen- 
tos conceptuales necesarios para abordar en su complejidad los problemas ambientales. ${ }^{4}$

\section{b) El enfoque de la politica ambiental}

Hasta ahora, las políticas ambientales se han caracterizado por un enfoque negativo: se ha tratado de prohibir, frenar o penalizar ciertos usos y abusos, es decir, de imponer restricciones y limitantes a las estrategias productivas establecidas. A partir de un marco normativo, por lo general de desarrollo insuficiente, se han impuesto sanciones o se han cancelado actividades. Sin embargo, la legislación ambiental se cumple en muy escasa medida en el contexto de América Latina. Las sanciones que, en el mejor de los casos, se logran imponer a los agentes económicos de la depredación ambiental se transmiten a los costos de producción, y el problema queda irresuelto. Los estudios de "impacto ambiental", independientemente de sus deficiencias metodológicas, se realizan en casos muy aislados, cuando los grandes proyectos llevan ya tal grado de avance que resulta prácticamente imposible detenerlos, por lo que se limitan a determinar acciones remediales de eficacia limitada. Es necesario actuar en una fase previa, en la que se definen las estrategias productivas, y hacerlo en un sentido propositivo. Se necesita un planteamiento de alternativas que incorporen una mayor racionalidad ambiental. La reorientación de las estrategias productivas tiene que probar que los requerimientos ambientales son perfectamente compatibles con las exigencias del desarrollo sostenible. Un trabajo de advocacy, basado en estímulos y en concertaciones, será tan importante como el trabajo normativo y sancionador.

\section{c) Los plazos de la política ambiental}

El movimiento ambientalista ha concentrado su atención en los problemas estructurales de largo plazo, dando a veces implícitamente la impresión de que casi no valdría la pena actuar con base en estrategias de corto plazo. Sin embargo, las demandas políticas en relación con el medio ambiente se centran sobre todo en problemas concretos y puntuales, que reclaman respuestas de verificación

\footnotetext{
+ En este sentido están trabajando la International Federation of Institutes for Advanced Studies (IFIAS), y el International Institute of Applied Systems Analysis (ilASA). La investigación teórica sobre "sistemas complejos" tiende a constituir un subprograma ineludible en el marco de los grandes programas ambientales, como el que está tratando de impulsar IFIAs: "The human response to global change".
} 
inmediata. La política ambiental no puede desatender estas demandas. Se necesita articular las acciones a corto, mediano y largo plazo, para estructurar una estrategia ambiental unitaria. Sin la componente de corto plazo, la política ambiental vería mermada su capacidad de contribuir a la superación de la crisis.

\section{d) Las escalas de intervención}

La atención al medio ambiente ha tendido en los hechos a priorizar una escala global de análisis e intervención. Como lo ha planteado el pensamiento ambientalista latinoamericano, el abordamiento completo de la cuestión ambiental requiere de una transformación del estilo de desarrollo predominante. Pero esta transformación, si es que se logra emprender, no se consigue al instante y por decreto. Resultaría paralizante esperar a que se produjeran las grandes transformaciones en el conjunto de las estrategias productivas para recién entonces plantear, a gran escala, el problema ambiental. La estrategia del todo o nada resulta estéril frente a una alternativa más realista, basada en la acción cotidiana, posibilista, centrada incluso en aspectos locales de naturaleza puntual. Se deben aprovechar los espacios de acción que hoy pueden ser marginales o intersticiales en relación con el sistema productivo dominante. Esta estrategia, que revaloriza la intervención local, permite impulsar la concientización social a través de su efecto demostrativo, y acelerar la transición hacia un estilo de desarrollo no depredador. Entre el efecto ambiental global de un estilo de desarrollo y la multiplicidad de sus manifestaciones locales existe una compleja red de mediaciones sin cuya comprensión resulta imposible avanzar.

La crisis ha impuesto al ambientalismo el reto de dar respuestas en función del aqui y ahora. Los nuevos requerimientos de eficacia exigen superar el viejo y falso dilema, que pudiéramos caracterizar como la versión medioambiental de apocalipticos vs. integrados. El ambientalismo ganaria en operatividad si además de denunciar las tendencias homogeneizantes del estilo de desarrollo dominante, que aplica estrategias productivas estándares en contextos socio-ambientales muy complejos y diversificados, plantease opciones diferenciales en función de las condiciones locales concretas. La especificidad de los factores ecológicos y sociales de carácter local sólo se puede percibir a través de una gestión ambiental descentralizada. La descentralización se presenta así como la única opción que permitiria un mejor aprovechamiento de los recursos existentes, a través de una gestión más apegada al terreno, y más en contacto con la realidad social. Sólo a nivel local es factible una per- 
cepción real, exenta de distorsiones tecnoburocráticas, de las necesidades reales de la población y de la componente ambiental de los problemas del desarrollo. La efectiva participación de los pobladores sólo es posible cuando se han reducido al mínimo las mediaciones burocráticas entre las instancias de toma de decisiones y la realidad socio-ambiental local. Aunque la gestión ambiental no haya podido todavia consolidarse ni siquiera sobre bases centralistas, el ambientalismo presenta hoy claras exigencias descentralizadoras. Los argumentos ambientales refuerzan la necesidad de potenciar las instancias primarias locales de la estructura político-administrativa, que en América Latina se identifican con las municipalidades. Se produce así una neta convergencia entre el movimiento ambientalista y el municipalista.

\section{Hacia una política ambiental municipal}

Reconociendo en la descentralización una aspiración común a ambientalistas y a municipalistas, convendrá disolver algunos equivocos al respecto. Descentralizar no es exactamente lo contrario de centralizar, no consiste en desandar el camino recorrido bajo una orientación centralista, para fomentar autarquías cantonales, o propiciar situaciones de desintegración nacional que tanto costaron de superar en la región. La descentralización es la superación, no la simple negación, del centralismo hoy dominante, a través de la construcción de una estructura más compleja del Estado, que lo vuelva más estable frente a los requerimientos y a las tareas actuales. Para los gobiernos locales, el proceso descentralizador implica una doble articulación; por una parte, con la sociedad civil organizada, por la otra, con las demás instancias del Estado. El simple fortalecimiento municipal carecería de sentido en ausencia de este doble proceso articulador. Así concebida, la descentralización permitiría a las municipalidades asumir un nuevo papel como promotoras del desarrollo a nivel local, incluyendo en este empeño a la gestión ambiental. Pero la ausencia de un proceso descentralizador no exime a las municipalidades de sus actuales responsabilidades en materia de desarrollo y medio ambiente. Los gobiernos locales tienen todavía en la región un campo nada despreciable de acción ambiental, incluso en aquellos casos en que su papel haya quedado reducido a la gestión de algunos servicios urbanos. La incidencia ambiental de la prestación de los servicios urbanos puede llegar a ser muy importante para la dinámica del medio ambiente en un territorio muy amplio. Resulta decisivo al respecto el enfoque tecnológico con el que se encara dicha prestación de servicios. En la actualidad, para la mayoría de 
los gobiernos locales, el problema de la selección tecnológica no llega ni siquiera a plantearse, puesto que las opciones técnicas convencionales se conciben como constantes indiscutibles que configuran el horizonte de lo imaginable. El conservadurismo tecnológico municipal conduce incluso a percibir las necesidades sociales en términos de las técnicas dominantes, a partir de las cuales se formulan los problemas. Así, por ejemplo, el punto de partida para una acción municipal suele ser la "carencia de alcantarillado" en un determinado barrio; no se plantea la "gestión de sus residuos liquidos", que podría llevarse a cabo a través de una multiplicidad de técnicas bien probadas. Del mencionado conservadurismo participan por cierto los msu cuyas demandas también se formulan en términos de las técnicas convencionales. Sin embargo, éstas últimas presentan con frecuencia implicaciones sociales o ambientales que las vuelven inadecuadas en los contextos concretos en los que se aplican. Surgen problemas de costeabilidad, de contaminación, de ruptura del equilibrio ecológico, que tienden a verse, erróneamente, como el costo inevitable del desarrollo de los asentamientos. La prestación de los servicios urbanos básicos - abastecimiento de agua potable, disposición de aguas servidas, recogida y procesamiento de residuos sólidos, transporte, limpieza urbana - no tiene por qué ser en sí misma depredadora del medio ambiente, y no lo será si se realiza con base en un enfoque de tecnologías adecuadas. Se entenderá que una tecnología es adecuada cuando soluciona necesidades sociales reales, y se adapta racionalmente a las condiciones del medio ambiente y de la sociedad que la implementa. A partir del compromiso con una mayor racionalidad tecnológica podrán las municipalidades desarrollar su política ambiental. Para cada uno de los servicios municipales existe un amplio abanico de opciones y alternativas técnicas viables, incluyendo a las que conocemos como convencionales. Se trata de operar una verdadera selección tecnológica, con criterios objetivos de racionalidad, que en función de las características de cada caso concreto y con la participación de las comunidades involucradas, permita elegir la mejor de las opciones existentes, sea o no "convencional". La implantación de técnicas alternativas, no convencionales, resulta siempre más fácil en el nivel local que en el nacional. La innovación tecnológica puede ensayarse a escala municipal sin incurrir en costos y riesgos inaceptables. Este proceso, que conseguiria movilizar recursos hoy desaprovechados, sólo podria hacerse efectivo mediante una capacitación de los recursos humanos municipales que rebase los paradigmas convencionales. El problema no es sólo cuantitativo; no se trata simplemente de que "falten técnicos". Es preciso revisar los 
paradigmas profesionales de esos técnicos, en función de los requerimientos impuestos por la nueva situación de las municipalidades. En algunas circunstancias, se podrán suplir costosas infraestructuras con organización. En este sentido, se cuenta todavía en la región con una tradición de respuesta colectiva, comunitaria, que desde los tiempos de la última guerra mundial se ha ido perdiendo en los países industrializados.

La gran mayoría de las municipalidades retiene todavía un cierto control de la planificación física del asentamiento principal dentro de su jurisdicción. En esta capacidad planificadora reside un instrumento decisivo para la política ambiental municipal. Las autoridades locales están, en principio, en condiciones de controlar ciertos aspectos de la transformación del medio natural, mediante la calificación de usos del suelo, zonificación, determinación de densidades edilicias, etc. En la planificación urbana municipal, tanto como en la nacional, se manifiesta la necesidad de incorporar la dimensión ambiental, a la que hoy se presta una atención insuficiente.

La comprensión, por parte de las municipalidades, del metabolismo real de sus asentamientos permitirá formular estrategias para su transformación en función de las necesidades y de los objetivos del desarrollo local. Los flujos de materia y energía que entran y salen del sistema constituido por un asentamiento sólo están parcialmente bajo control municipal, por lo que se impone una política de concertación, que será tanto más eficaz cuanto mayor sea la representatividad, la legitimidad y la capacidad normativa, administrativa y técnica de las autoridades municipales. Estas últimas, en la medida en que puedan asumir nuevas capacidades y competencias, podrán ampliar su campo de acción hacia la totalidad de su área jurisdiccional, incluyendo las zonas rurales, e incidir en la orientación del conjunto de las estrategias productivas locales. Una municipalidad fortalecida podría también impulsar algunas acciones estratégicas, como la de modificar la demanda efectiva de bienes y servicios, mediante una transformación concertada de los patrones de consumo locales. La intervención por el lado de la demanda constituye de hecho uno de los mecanismos más eficaces para reordenar las estrategias productivas y por ende, cambiar las modalidades de relación con el medio ambiente.

La mayor eficacia de la actuación municipal la hará objeto de mayores pugnas políticas, sustentadas en el campo de los intereses locales afectables. Los posibles conflictos se resolverán en función de la correlación existente de fuerzas; además de inevitables, cstos conflictos serían signo de la nueva vitalidad de las municipalidades. 


\section{Síntesis}

a) En América Latina y en el marco de la lucha por superar la profunda crisis de los años ochenta, cada país tendrá que evaluar -en función de su situación concreta- la posibilidad de promover una reforma descentralizadora y democrática del Estado. Esta reforma, necesaria tanto por razones de política general como de política ambiental, es hoy imprescindible para dar impulso a un nuevo proceso de desarrollo y no podrá limitarse al plano administrativo. La reforma implicaría una redefinición práctica de los objetivos nacionales; no tendría sentido reformar el Estado para volver a recorrer un camino que condujo a la crisis actual. La propia puesta en marcha del proceso descentralizador contribuiría a una maduración conjunta de la sociedad civil y del Estado.

b) En la región, los municipios representan los elementos de base para cualquier proceso descentralizador. Las municipalidades requieren de un reforzamiento urgente y de una revisión de su situación autonómica en el plano legal, político, administrativo, hacendario y técnico, para poder asumir su papel como promotoras del desarrollo a nivel local. Se necesitan nuevos y poderosos cauces de participación en el quehacer municipal, así como mecanismos más claros y eficaces para ejercer competencias concurrentes con las de otras instancias del Estado.

c) En ausencia de un proceso descentralizador claro y explícito, las municipalidades de la región siguen teniendo responsabilidades nada despreciables en lo que respecta a la política ambiental, que no siempre están asumiendo en la actualidad. Entre los instrumentos de los que todavía suelen disponer y que no utilizan a fondo, destacan el control del estilo tecnológico con el que se resuelve la prestación de algunos servicios urbanos básicos y el control de la planificación física del asentamiento principal. La adopción de un enfoque tecnológico más adecuado y la incorporación de la dimensión ambiental en la planificación municipal constituirian un enorme avance cuya viabilidad exigiría no tanto grandes transformaciones jurídicas, como un proceso no convencional de capacitación de los recursos humanos de las municipalidades. En la medida en que éstas últimas se reforzaran, especialmente en el plano de sus hoy raquíticas finanzas, podrían extender su escala de intervención a la totalidad de su jurisdicción espacial, ya sea urbana, rural o mixta, e incluso asumir su parte de responsabilidad en la orientación de los problemas del desarrollo en un territorio más amplio.

d) Para desarrollar políticas ambientales propias, los municipios de la región tendrian mucho que ganar reforzando el asociativismo 
y la cooperación intermunicipal, tanto en el nivel nacional como en el internacional. Para ser efectiva, la colaboración necesita basarse en un conjunto de intereses compartibles, no en una simple retórica municipalista. Se impone pues una tipología elemental de situaciones, que garantice una semejanza de intereses a pesar de la enorme diversidad internacional de situaciones político-jurídicas. Se sugieren los siguientes criterios para precisar esta tipología:

1. sistema de asentamientos y tamaño del asentamiento principal;

2. caracterización ecológica del territorio; a los cuales eventualmente se podría agregar:

3. orientación productiva dominante.

\section{Algunas referencias bibliográficas}

El tema específico de la política ambiental municipal carece, en sí mismo, de un gran respaldo bibliográfico. Para abordarlo es preciso referirse a dos conjuntos separados de fuentes documentales de índole más general. Por una parte, se dispone de un enorme acervo de documentos que se refieren a la situación social, política, jurídi$\mathrm{ca}$, administrativa y económica de los municipios latinoamericanos, y a su inserción en la estructura del Estado. Por otra parte, hay que hacer referencia a un conjunto mucho más modesto de documentos centrados en la política ambiental en general.

El problema teórico de la reforma descentralizadora y democrática del Estado está tratado en forma excelente, y con amplia referencia a la interesante experiencia europea reciente, en Borja, J. (1984). Un primer análisis comparativo de la situación de las municipalidades en América Latina en relación con la planificación se hallará en Camacho, L. et al. (1985). Se consultarán con provecho al respecto las ponencias y conclusiones generales del Seminario Latinoamericano "Gobierno municipal/Gobierno nacional": SIAP (1984).

- En México, la revista Planeación Democrática, -hoy descontinuada-, que publicaba la Secretaría de Programación y Presupuesto, incluía a veces, en su sección "La planeación en el mundo", buenas sintesis de algunas situaciones nacionales, no sólo latinoamericanas, en relación con la estructura del Estado y la función planificadora, además de una abundante documentación acerca de la situación mexicana, centrada sólo en fuentes oficiales.

- Patrocinado por el Foro Nacional por Colombia, CLACso y el Instituto de Cooperación Iberoamericana, se celebró en junio de 1986 
en Bogotá-Tuluá, Colombia, un "Seminario Latinoamericano sobre los Municipios y los Gobiernos Locales".

- Más específico para nuestro tema fue el "1er. Simposio Iberoamericano sobre medio ambiente y municipio", celebrado en octubre de 1986 en Iguazú, Argentina, y que tuvo una segunda edición en julio de 1987 en Caracas, Venezuela, bajo el patrocinio del Concejo Municipal de Caracas y el Ministerio para las Administraciones Públicas, de España.

- En el campo de la legislación ambiental comparativa, Brañes, R. (1979) incluye una muy breve sección dedicada a los municipios.

La situación general del medio ambiente en la planificación del desarrollo fue objeto del XV Congreso Interamericano de Planificación: véase Sociedad Colombiana de Planificación (1986).

Para ser más especifico, el análisis tendría que detenerse en algunos casos nacionales.

- El caso de México resulta muy interesante. El Gobierno ha asumido para el sexenio 1982-1988 una política explícita de descentralización y reforma municipal, cuyos resultados sería necesario evaluar.

Una visión independiente y de conjunto de esta experiencia se encontrará en Martínez Assad y Ziccardi (1986). Véase también Ruiz Massieu M. (1986). Conviene consultar la colección completa de la revista Fortalecimiento y Desarrollo Municipal - hoy descontinuadapublicada hasta el núm. 28 por la Secretaría de Programación y Presupuesto (1983-1985), así como el conjunto de las publicaciones del Centro Nacional de Estudios Municipales (CNEM). Entre estas últimas se destacaría la de R. Olmedo et al. (1982), redactada antes de la reforma del art. 115 constitucional, que incluye una encuesta sobre la realidad de unos cien municipios mexicanos escogidos por su representatividad, CNEM (1985); la revista Estudios Municipales, del CNEM, y la revista El Municipio, también del propio CNEM, cuyo primer número apareció en enero de 1986. Sobre los problemas ambientales en relación con la descentralización, véanse los artículos de R. Olmedo en la Sección "La Crisis", en el periódico Excélsior. (1984).

Sobre la interesante experiencia tabasqueña de los "Centros Integradores", véase Gobierno del estado de Tabasco (1987).

- El único otro caso nacional que se mencionará aquí es el colombiano. Durante el gobierno del Dr. Belisario Betancur se inició una experiencia de involucramiento de los municipios en la politica ambiental: la Campaña Verde, promovida por INDERENA. Véanse al respecto: INDERENA (1985) y FESCOL-INDERENA (1986). Una breve introducción histórica a la situación del municipio colombiano se encon- 
trará en Santa E. (1969). Su situación actual se analiza desde el punto de vista jurídico en Vidal Perdomo, (1984), y, desde una perspectiva social, en las siguientes ponencias del ya mencionado Seminario de Bogotá: Viviescas, F. (1986), Velázquez F. (1986), Santana P. (1986).

\section{Bibliografía}

Borja, Jordi. "Descentralización: una cuestión de método" Revista Mexicana de Sociología, año XLVI, vol. XLVI, núm. 4, octubre-diciembre, 1984. Instituto de Investigaciones Sociales, UNAM, México, D.F

Brañes, Raúl. "La legislación ambiental en América Latina: visión comparativa", ponencia presentada en el Seminario sobre Medio Ambiente y Marco Leyal, (CifcA). San José de Costa Rica, noviembre, 1979.

CNEM "El municipio mexicano", Secretaria de Gobernación, México, D.F., 1985

Camacho, Luis, et al., "El municipio en América Latina y España". Sociedad Interamericana de Planificación. Correo Informativo, vol. 20, núms. 3 y 4, septicmbre-diciembre, 1985 .

Fescol-Inderena. "El libro de los Concejos Verdes". Fundación Fricdrich EbcrtInderena, Bogotá, 1986.

Gobierno del estado de Tabasco. "Manual de Centros Integradores" Edicion del (iobierno del estado de Tabasco. Villahermosa, Tab., 1987.

Inderena: "Manual de Recursos Naturales Renovables para Alcaldes, Corregiciores e Inspectores de Policia". Ministerio de Agricultura, Instituto Nacional de los Recursos Naturales Renovables y del Ambiente, Bogotá, 1985.

Martinez Assad, Carlos, Alicia Ziccardi. "El municipio entre la sociedad y el Estaldo". ponencia presentada en el Seminario Latinoamericano "Municipios y Ciobic:Ynos Locales", Bogotá/Tuluá, 1986.

Olmedo, Raúl et al. "El desafio municipal", primera ed. ICAl, 1982. Recolicion Cintro Nacional de Estudios Municipales, Secretaria de Gobernación, Mexico, D.F., 1985.

Rios del Castillo, Luis, "Relaciones del municipio con el gobicrno nacional an al l'crú", ponencia presentada en el Seminario Stw de Morelia, Mich. 1984

Ruiz Massieu, Mario, "El nuevo municipio mexicano". Boletín mexicano de derecho comparado, año xix, núm. 55, enero-abril, 1986, Instituto de: Investigacionc:s Il ridicas, UNAM, México, D.F.

Santa, Eduardo, "Realidad y futuro del municipio colombiano", Universidad Nacional, Dirección de Divulgación Cultural, Bogotả, 1969.

Santana, Pedro, "Crisis municipal, movimientos sociales y reforma politica (an Colombia". Seminario Latinoamericano "Municipios y gobiernos locales", Bogotai Tu luá, 1986.

Siap. "Seminario Latinoamericano: Gobierno municipal/Gobierno nacional. (onclusiones generales". Sociedad Interamericana de Planificación, Morclia, Mich. 1964.

Sociedad Colombiana de Planificación, "El medio ambiente en la planificación de!

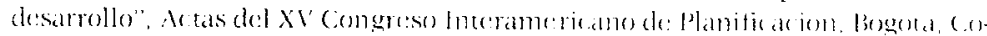
lombia, 1986.

Velásquez, Fabio E., "Crisis municipal y participación ciudadana en Colombia". Se:minario Latinoamericano "Municipios y gobiernos locales", Bogotä/Tulua, 1986.

Vidal Perdomo, Jaime, "El municipio y el Estado en el sistema juridico colombiano" Seminario sым, Morelia, Mich. 1984.

Vivescas, Fernando, "Identidad municipal v cultura urbana", ponencia presentada en el Seminario Latinoamericano "Municipios y gobiernos locales". Bogota "Tuluá, 1986. 
